\title{
Can use of pictograms reduce liquid medication administration errors by mothers? An interventional study
}

\author{
Pawan Patidar ${ }^{1}$, Aditya Mathur ${ }^{1}$ and Ashish Pathak ${ }^{1,2,3^{*}}$ (1)
}

\begin{abstract}
Background: Liquid medication dosing errors (LMDE) made by caregivers affect treatment in children, but this is not a well-studied topic in many low-and middle-income countries including in India.

Methods: An intervention study was conducted among mothers attending a pediatric outpatient clinic of a tertiary care setting in Ujjain, India. The mothers randomly measured 12 volumes of a paracetamol liquid preparation by using a dropper ( 0.5 and $1 \mathrm{~mL}$ ), measuring cup (2.5 and $5 \mathrm{~mL}$ ), and calibrated spoon (2.5 and $5 \mathrm{~mL}$ ) each with two instructions - oral-only measurement session (OMS) and oral plus pictogram measurement session (OPMS, the intervention). The main outcome was dosing error prevalence. The effectiveness of the intervention was assessed by measuring effect size. Risk factors for maximum LMDE were explored using backward multivariate logistic regression models. A $P$ value of $<0.05$ was considered statistically significant.

Results: In total, 310 mothers [mean ( \pm SD) age, 30.2 ( \pm 4.18 ) years] were included. LMDE prevalence in the OMS versus OPMS for dropper $0.5 \mathrm{~mL}$ was $60 \%$ versus $48 \%$; for I $\mathrm{mL}$ dropper was $63 \%$ versus $54 \%$; for $2.5 \mathrm{~mL}$ cup $62 \%$ versus 54\%; for 2.5 calibrated spoon 66\% versus 59\%; $5 \mathrm{~mL}$ cup $69 \%$ versus $57 \%$; and $5 \mathrm{~mL}$ calibrated spoon $68 \%$ versus $55 \%$. Comparing OMS with OPMS, underdosing was minimum with the calibrated spoon for $2.5 \mathrm{~mL}$ (OR 4.39) and maximum with the dropper for $1 \mathrm{~mL}$ (OR 9.40), and overdosing was minimum with the dropper for $0.5 \mathrm{~mL}$ (OR 7.12) and maximum with the calibrated spoon for $2.5 \mathrm{~mL}$ (OR 13.24). The effect size $\left(\mathrm{d}_{\text {Cohen }}\right)$ of the intervention OPMS was 1.86-6.4. Risk factors for the most prevalent dosing error, that is, with the calibrated spoon for $2.5 \mathrm{~mL}$, were increasing age of the mother (aOR 1.08; $P=0.026)$ and nuclear family (aOR 2.83; $P=0.002)$. The risk of dosing errors decreased with higher education of the mothers.
\end{abstract}

Conclusions: Pictograms can effectively minimize LMDE even in less educated mothers.

Keywords: Dose administration, Dosing errors, Dosing devices, Pictograms

\section{Background}

The American National Coordinating Council for Medication Error Reporting and Prevention defines medication errors as "any preventable event that may cause or

\footnotetext{
*Correspondence: ashish.pathak@ki.se; ashish.pathak@kub.uu.se; ashish. jpathak@gmail.com

${ }^{1}$ Department of Paediatrics, Ruxmaniben Deepchand Gardi Medical

College, Ujjain, Madhya Pradesh 456010, India

Full list of author information is available at the end of the article
}

lead to inappropriate medication use or patient harm while the medication is in the control of the healthcare professional, patient, or consumer. Such events may be related to professional practice, healthcare products, procedures, and systems including prescribing; order communication; product labelling, packaging and nomenclature; compounding; dispensing; distribution; administration; education; monitoring; and use" [1]. 
Oral liquid medications are often preferred for children because of their ease of administration. Weight-based dosing is a norm in pediatric prescribing, and liquid medications provide a pediatrician more flexibility and ease in prescribing individualized dosing to children having different body weights. This individualized and accurate dosing decides treatment efficacy and effectiveness [2]. Studies have suggested that over $40 \%$ caregivers make some liquid medication dosing errors (LMDE) both in resource-rich and resource-poor settings [2-10]. Medication errors may contribute toward treatment failure and many other adverse events including death [11].

LMDE occur mostly due to lack of experience among parents in administering liquid medications or due to the dosing device $[4,12]$. Liquid preparations are more vulnerable for dosing errors as they are more susceptible to dosage errors associated with the dosing device [9]. Many caregivers, including those in low- and middle-income countries (LMICs), commonly use substandard household items such as teaspoons and tablespoons or cups for measuring and administering liquid medications instead of standard liquid medication delivery devices such as medicine cups, droppers, calibrated spoons, and syringes $[6,9,13]$. These standard delivery devices may be lost by parents at home or become dirty, especially in LMICs. An Indian study showed that a kitchen spoon was used commonly by caregivers for measuring liquid medications, resulting in $40 \%$ parents making dosing errors in pediatric liquid formulations [6].

Studies conducted in high-income countries have reported that among the various strategies used for reducing medication errors, the pictogram-based intervention is found to be the most beneficial and is used for medication counseling, which resulted in reduced medication dosing errors and improved medication and dosing adherence among caregivers with a low socioeconomic status as well as with lower education [4, 14-17]. However, evidence that pictograms will be an effective intervention in LMICs, including India, is lacking. Therefore, the research question addressed in the present study was: what is the prevalence of liquid medication errors with various measuring devices when oral only instructions were used to instruct mother's about liquid medication dosing versus pictograms along with oral instructions, under study conditions in Ujjain, India? and can pictograms effectively minimize dosing errors?

\section{Methods}

\section{Study site and settings}

This cross-sectional study was conducted during MarchMay, 2017 in the Ujjain district of the state of Madhya Pradesh (MP), India. MP is the fifth largest Indian state and has a low human development index of 0.624 [18].
Ujjain has a population of 1.9 million, with approximately $61 \%$ people living in rural areas [19]. Other demographic characteristics of the district are provided in National Family Health Survey-4 [19]. The study was conducted between 9:00 a.m. to 1:00 p.m. in the pediatric outpatient department (OPD) of RD Gardi Medical College, Ujjain, a tertiary care institute, managed by a not-for-profit trust. Data were collected from the OPD for at least two days per week to cover a full week. Thus, a convenience sampling of mothers presenting with their children to the pediatric OPD was performed. The mothers were approached in the outpatient waiting area and were asked to participate in the study after describing the study. Written informed consent in Hindi was obtained from the participating mothers.

\section{Inclusion and exclusion criteria}

Mothers of children presenting for care in the pediatric clinic and those who were responsible for medication administration in the household were included. Mothers with a child presenting with an emergency, those with auditory-ocular problems, and those refusing to participate were excluded.

\section{Sample size calculation}

The sample size was calculated using Stata (Version 12.0, Statacorp. Texas, USA). We assumed that parents receiving the text plus pictogram instruction would have $20 \%$ less LMDE than those receiving the text-only instruction. Thus, to detect reduction in the error rate of $20 \%$ with a power of $80 \%$ and two-sided alpha of 0.05 , the minimum sample size is approximately 300 patients, both for the sample as a whole and for subgroup analysis based on dosing literacy.

\section{Data collection}

Mothers were invited to participate in a pre-measurement session and two measurement sessions-a baseline measurement session and an intervention session. Data were collected by interviewing the mother in paper forms comprising a questionnaire, which consisted of questions related to all three sessions.

\section{Pre-measurement}

This section of the questionnaire assessed the sociodemographic characteristics and perception of the mothers about using measuring devices. The mothers were interviewed regarding the medication dosing devices they have used until now and to rate these devices for the ease of use and accuracy. The reason for their choice was explored in subsequent questions. 


\section{Baseline measurement session}

In the baseline measurement session all the participating mothers, irrespective of their literacy level, were read out instructions for measurement of a liquid medication in $\mathrm{mL}$ and drop format. The baseline measurement session was call oral only measurement session (OMS). The conditions under which this oral only measurement session was undertaken is mentioned later.

\section{Intervention}

Pictogram to explain the liquid medication dosing so as to reduce dosing errors was the intervention. The intervention measurement session was called oral instruction plus pictogram measurement session (OPMS) [17]. In the OPMS the mothers were read out the instructions (as in the OMS) along with a pictographic illustration of the dose using a hand-drawn pictogram dosing diagram and were asked to remeasure the dose using the provided test-pictogram instruction (OPMS).

\section{Study tasks}

Each mother participated in both OMS and OPMS and was asked to measure a specified dose of paracetamol of the same brand in drop and suspension using three dosing devices: a dropper for drops, and a measuring cup and calibrated spoon for suspension. The participants in each session measured: two doses with each device. Thus, each participating mother measured 12 times (Additional file 1: Table S1 and Additional file 2: Figure S1). The dose and device used to measure was randomly assigned for each participating mother.

\section{Study conditions}

The instructions were read in the same sequence regardless of the medication dose during both OMS and OPMS. An example of pictograms used in the study is presented in Additional file 2: Figure S1. No communication took place between the mothers and researcher during mothers' task to remeasure the dose. No time limit was specified for completing the entire protocol. No incentive was provided to the caregiver for study participation (Fig. 1).

\section{Measurement of dosing error}

The medication volume measured by the mother was recorded using a variable volume micropipette (Eppendorf India Private Limited, Chennai, India). The difference between the volume measured by the mother and the standard volume measured using the micropipette was used to calculate the measuring error.

\section{Fidelity of intervention}

The principal investigator trained the research assistants to maintain the fidelity of the intervention. The intervention module consisted of a 3-h training session involving a discussion on all text messages and pictograms. The concepts were reinforced by allowing the research assistants to engage in role-playing. The session was repeated once every fortnight during the study period. A training manual was used to articulate the contents and delivery of the pictogram intervention. The mothers' receipts of the intervention were assessed on the basis of reduction in underdosing or overdosing errors after the intervention.

\section{Outcome measure}

Dosing error was the primary outcome variable; error magnitude was determined by volume measurement as defined above. A measurement deviation of $>20 \%$ was considered a dosing error. A large dosing error was defined as an error double of the threshold dosing error, viz. $>40 \%$ [20]. The measured dosing errors included underdosing or overdosing error.

\section{Statistical analysis}

Data were entered using OpenEpi, Version 3 [21]. The data analysis was done using Stata (Version 12.0, Statacorp. Texas, USA). Descriptive statistics were calculated for each variable. Based on normalized data, baseline characteristics of the TPMS and TOMS were compared using paired $t$ tests and one-way analysis of variance as appropriate. The significance level was set at $P<0.05$.

Multivariate logistic regression was performed to investigate predictors of LMDE while controlling for relevant covariates. The dependent variable for multivariate logistic regression models was the device and volume identified with maximum error. Adjusted odds ratios (aORs) of the dose error for various covariates having a $P$ value of $<0.1$ were calculated using the backward multivariate logistic regression model. $P<0.05$ was considered statistically significant.

\section{Ethical approval}

The study was approved by the institutional ethical review board (IEC Ref. No- IEC/RDGMC/171).

\section{Results}

The study included 310 mothers with a mean $( \pm S D)$ age of $30.2( \pm 4.18)$ years. The mean $( \pm S D)$ size of the family was $4.94( \pm 1.74)$ members, with the mean $( \pm S D)$ number of children being $1.75( \pm 0.79)$. The mean $( \pm$ SD) age 
Table 1 Socio-demographic characteristics of the mothers and their families $(n=310)$ included in the study in Ujjain, India

\begin{tabular}{|c|c|c|c|}
\hline Independent variables & $n(\%)^{a}$ & Independent variables & $n(\%)^{a}$ \\
\hline Locality & & Mother occupation & \\
\hline Urban & $120(39)$ & Housewife & $133(43)$ \\
\hline Rural & $190(61)$ & Self employed & $30(10)$ \\
\hline Home type & & Farm worker & $126(41)$ \\
\hline Kuccha & $65(21)$ & Labor & $7(2)$ \\
\hline Pukka & $98(32)$ & Office work & $14(4)$ \\
\hline Kuccha-Pukka & $147(47)$ & Father education & \\
\hline Family type & & Uneducated-primary school & $9(3)$ \\
\hline Nuclear & $193(62)$ & Middle school-higher secondary & $160(52)$ \\
\hline Joint & $117(38)$ & Graduate-post graduate & $141(45)$ \\
\hline Number of children & & Mother occupation & \\
\hline 1 & $137(44)$ & Unemployed & $1(1)$ \\
\hline 2 & $121(39)$ & Self employed & $146(47)$ \\
\hline$>2$ & $52(17)$ & Farm worker & $132(42)$ \\
\hline Overcrowding & & Labor & $4(2)$ \\
\hline Yes & $79(25)$ & Office work & $27(8)$ \\
\hline No & $231(75)$ & & \\
\hline \multicolumn{4}{|l|}{ Mother education } \\
\hline Uneducated-primary school & $106(34)$ & & \\
\hline Middle school-higher secondary & $150(48)$ & & \\
\hline Graduate-post graduate & $54(17)$ & & \\
\hline
\end{tabular}

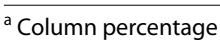

of the father was $34.38( \pm 3.6)$ years. Table 1 presents the sociodemographic characteristics of the participating mothers. The most preferred dosing device for measuring liquid medications was the measuring cup (39\%). The most common reason for selecting a dosing device was the ease of use $(54 \% ; n=167)$. Table 2 presents other practices and perceptions of mothers regarding administering liquid medications to their children.

The percentage error in measuring the correct dose for $0.5,1,2.5$, and $5 \mathrm{~mL}$ by the dropper, cup, and calibrated spoon improved from $60 \%, 63 \%, 62 \%, 66 \%, 69 \%$, and $68 \%$, respectively, in the OMS to $12 \%, 9 \%, 8 \%, 7 \%, 12 \%$, and $13 \%$, respectively, in the OPMS. The corresponding ORs are listed in Table 3.

In the OMS, the prevalence of correct, overdose, and underdose for 0.5 and $1 \mathrm{~mL}$ using the dropper was $40 \%$, $44 \%$, and $15 \%$ and $37 \%, 39 \%$, and $24 \%$, respectively. The prevalence of correct, overdose, and underdose using the measuring cup was $38 \%, 46 \%$, and $16 \%$ and $34 \%, 55 \%$, and $12 \%$, respectively (Table 4 ). The prevalence of correct, overdose, and underdose using the calibrated spoon is shown in Table 4. Figure 2 shows the Whisker-box plots of medication errors for all measuring devices and medication doses used in the study.

The frequency of large dosing errors were maximum $(91 \%, \mathrm{n}=163)$ when the calibrated spoon was used to measure $2.5 \mathrm{~mL}$ of paracetamol, therefore a logistic regression model was run to explore the independent factors associated with the device with maximum dosing error. Table 5 presents the multiple logistic regression model for predictors of errors while measuring a dose of $2.5 \mathrm{~mL}$ using the calibrated spoon, and the predictors included age of the mother, type of family-nuclear versus joint, education status of mother-uneducated and primary schooling versus middle school and secondary school versus graduate and postgraduate. The Receiver Operator Curve of the final model was 0.826 , showing an excellent model fit. The Hosmer-Lemeshaw test showed that chi-square was $13.77(P=0.087)$. A high $P$ showing good model calibration was observed. The proportion of variance explained by the model with three independent variables was $29.6\left(R^{2}\right)$.

\section{Discussion}

In this study, the prevalence of dosing errors ranged from 60 to $69 \%$ with the different measuring devices, namely dropper, cup, and calibrated spoon, and with different doses, namely $0.5,1,2.5$, and $5 \mathrm{~mL}$. In other studies, the prevalence of LMDE was more than $40 \%$ and ranged from 40 to $60 \%$ with different instruments and different doses [8, 22-26]. However, LMDE prevalence was higher in our study. A possible reason for the high error rate can 
Table 2 Practices and perceptions of the mothers $(n=310)$ regarding administering liquid medication to their child

\begin{tabular}{|c|c|}
\hline Variable & $\mathrm{n}(\%)^{\mathrm{a}}$ \\
\hline \multicolumn{2}{|l|}{ Do you have past experience in giving liquid medication? } \\
\hline Yes & $293(95)$ \\
\hline No & $17(5)$ \\
\hline \multicolumn{2}{|l|}{ Have you experienced difficulty in the last medication administration? } \\
\hline Yes & $198(64)$ \\
\hline No & $112(36)$ \\
\hline \multicolumn{2}{|c|}{ What is the most common device preferred by you to measure liquid medication? } \\
\hline Calibrated spoon & $9(3)$ \\
\hline Teaspoon & $70(22)$ \\
\hline Syringe & $8(3)$ \\
\hline Measuring cup & $123(39)$ \\
\hline Dropper & $28(9)$ \\
\hline Bottle cap & $61(20)$ \\
\hline Direct sip from bottle & $11(4)$ \\
\hline \multicolumn{2}{|l|}{ What is the most important reason for choosing a measuring device? } \\
\hline The medicine can be measured accurately with the device & $41(13)$ \\
\hline It is easy to find the device at home & $56(18)$ \\
\hline Device is easy to use & $167(54)$ \\
\hline Device reduces risk of spilling the medicine & $46(15)$ \\
\hline \multicolumn{2}{|c|}{ Did you adjust the dose according to physician instruction in the last medication administration? } \\
\hline Yes & $146(47)$ \\
\hline No & $164(53)$ \\
\hline \multicolumn{2}{|c|}{ Did you have difficulty in understanding the dosing instruction given by the doctor? } \\
\hline Yes & $270(87)$ \\
\hline No & $40(13)$ \\
\hline
\end{tabular}

a Column percentage

Table 3 Prevalence of dosing errors committed by mothers, binomial effect size display, odds ratios of reduction in dosing errors and Cohen's d (effect size) of the pictogram intervention (TPMS)

\begin{tabular}{|c|c|c|c|c|c|c|c|c|}
\hline \multirow[t]{3}{*}{ Device } & \multirow[t]{3}{*}{ Doses (mL) } & \multicolumn{2}{|l|}{ TOMS } & \multicolumn{2}{|l|}{ TPMS } & \multirow[t]{3}{*}{ BSED (\%) } & \multirow[t]{3}{*}{$O R^{* *}(95 \% \mathrm{Cl})$} & \multirow{3}{*}{$\begin{array}{l}\text { Effect size } \\
\left(d_{\text {cohen }}\right)\end{array}$} \\
\hline & & Incorrect & Correct & Incorrect & Correct & & & \\
\hline & & $\mathrm{n}=310(\%)^{\mathrm{a}}$ & $\mathrm{n}=310(\%)^{\mathrm{a}}$ & $\mathrm{n}=310(\%)^{\mathrm{a}}$ & $\mathrm{n}=310(\%)^{\mathrm{a}}$ & & & \\
\hline \multirow[t]{2}{*}{ Dropper } & 0.5 & $185(60)$ & $125(40)$ & $38(12)$ & $272(88)$ & 48 & $10.55(7.05-16.02)$ & 1.86 \\
\hline & 1 & $196(63)$ & $114(37)$ & $28(9)$ & $282(91)$ & 54 & $17.22(11.07-27.44)$ & 3.01 \\
\hline \multirow[t]{2}{*}{ Measuring cup } & 2.5 & $192(62)$ & $118(38)$ & $26(8)$ & $284(92)$ & 54 & $17.68(11.25-28.51)$ & 2.89 \\
\hline & 5 & $206(66)$ & $104(34)$ & $23(7)$ & $287(93)$ & 59 & $24.56(15.3-40.65)$ & 6.4 \\
\hline \multirow[t]{2}{*}{ Calibrated spoon } & 2.5 & $215(69)$ & $95(31)$ & $38(12)$ & $272(88)$ & 57 & $16.11(10.69-24.67)$ & 3.83 \\
\hline & 5 & $210(68)$ & $100(32)$ & $41(13)$ & $269(87)$ & 55 & $13.71(9.19-20.75)$ & 2.9 \\
\hline
\end{tabular}

Text only measurement session (TOMS) and text plus pictogram measurement session (TPMS); BSED: Binomial effect size display (intervention success); OR odds ratios $^{* *}(P<0.001$ for all OR displayed $)$

be the low education status of mothers and their failure to understand the test-only instructions.

In the pre-measurement session, the mothers were asked to report a preferred liquid dose measuring device and the reason for their preference. The measuring cup was the most preferred device, followed by non-standardized tools such as kitchen teaspoons and bottle caps. The most common reason for selecting the dosing instrument was the ease of use, followed by easy availability. Similar findings were reported in a study where a self-report 
Table 4 Prevalence of overdose and under dose in mothers $(n=310)$ during measuring sessions

\begin{tabular}{|c|c|c|c|c|c|c|}
\hline Dosing device & Dose $(\mathrm{mL})$ & Session $N=310$ & Overdose $\mathrm{n}(\%)$ & OR & Underdose $\mathrm{n}(\%)$ & OR \\
\hline \multirow[t]{4}{*}{ Dropper } & \multirow[t]{2}{*}{0.5} & TOMS & $137(44)$ & \multirow[t]{2}{*}{7.12} & $48(16)$ & \multirow[t]{2}{*}{7.93} \\
\hline & & TPMS & $31(10)$ & & $7(2)$ & \\
\hline & \multirow[t]{2}{*}{1} & TOMS & $122(39)$ & \multirow[t]{2}{*}{10.52} & $74(24)$ & \multirow[t]{2}{*}{9.40} \\
\hline & & TPMS & $18(6)$ & & $10(3)$ & \\
\hline \multirow[t]{4}{*}{ Measuring cup } & \multirow[t]{2}{*}{2.5} & TOMS & $142(46)$ & \multirow[t]{2}{*}{13.71} & $50(16)$ & \multirow[t]{2}{*}{4.95} \\
\hline & & TPMS & $18(6)$ & & $8(2)$ & \\
\hline & \multirow[t]{2}{*}{5} & TOMS & $170(55)$ & \multirow[t]{2}{*}{20.92} & $36(12)$ & \multirow[t]{2}{*}{6.65} \\
\hline & & TPMS & $17(5)$ & & $6(2)$ & \\
\hline \multirow[t]{4}{*}{ Calibrated spoon } & \multirow[t]{2}{*}{2.5} & TOMS & $179(58)$ & \multirow[t]{2}{*}{13.24} & $36(12)$ & \multirow[t]{2}{*}{4.39} \\
\hline & & TPMS & $29(9)$ & & $9(3)$ & \\
\hline & \multirow[t]{2}{*}{5} & TOMS & $168(54)$ & \multirow[t]{2}{*}{10.27} & $42(14)$ & \multirow[t]{2}{*}{5.24} \\
\hline & & TPMS & $32(10)$ & & $9(3)$ & \\
\hline
\end{tabular}

OR odds ratio; all rate ratios were statistically significant; $(P<0.001$ for all OR displayed $)$

5-item survey was used to assess participants' perceptions and preferred dosing instruments, that is, syringes and dosing cups [27]. Most (87\%) participants reported cups as the preferred tool, as it is easy to use [27].

Major dosing errors in our study were committed during the OMS when mothers measured small volumes. Maximum (69\%) errors were observed with calibrated spoons. While measuring large volumes, equal number of dosing errors were committed with calibrated spoons and measuring cups (68\% in both). A similar finding was reported in a study conducted by the American Association of Poison Control Centers [24]. In New York, a randomized controlled experiment reported that a total of $84 \%$ parents made $\geq 1$ dosing error and that the errors were more observed with cups than with other dosing devices, especially for smaller doses [26]. Other studies have also reported that cups were the most common device used to measure small volumes $[4,25,28]$. A calibrated spoon was another dosing tool that was identified to be associated with the risk of dosing errors while measuring small doses of $2.5 \mathrm{~mL}$. In the present study, majority of the dosing errors $(69 \%$; OR $16.11 ; P<0.001)$ were committed with the calibrated spoon, and these results are similar to those of another study, which reported $50 \%$ of the participants committing error when using a calibrated spoon [29]. The possible reasons for the high error rate in our setting were that calibrated spoons are less frequently used by Indian mothers and very few Indian pediatric medications come with calibrated spoons. For a large dosing error while measuring small volumes $(2.5 \mathrm{~mL})$, calibrated spoons were superior to other dosing devices used in the study. Similarly, another study reported that calibrated devices are associated with higher risk of parents committing a large dosing error while measuring small volumes $(<5 \mathrm{~mL})$ [27].
Poor maternal education results in poor health literacy. Health literacy and socioeconomic status of families were found to be strongly associated with dosing errors in studies $[26,30,31]$. The mothers in our study with a poor education status committed more errors than those with a better education status. Communication problems between patients and healthcare providers can significantly affect dosing errors $[17,32,33]$. A better communication between patients and providers can minimize dosing errors among mothers with a poor socioeconomic status and education status [17, 32, 33]. Improved health communication can prevent dosing error-induced adverse drug reactions by $72 \%$ [31].

In our study, pictogram interventions reduced dosing errors by $48-54 \%$ points and improved mothers' understanding of dosing. Incorporating pictorial aids into verbal medication counseling or text-based instructions was more beneficial than using the single approach alone [34]. This finding was similar to those of other studies in which pictogram interventions significantly reduced dosing errors [34]. In our study, mothers who received textonly (versus text and pictogram) instructions made most dosing errors with $2.5 \mathrm{~mL}$ measurement when using a calibrated spoon $[\mathrm{OR}=16.11$ (10.69-24.67)]. A similar finding has been reported previously [34].

Potential strategies for reducing dosing errors include the use of a health literacy informed approach to improve healthcare provider communication concerning medication instructions with caregivers through advanced counseling strategies and standardized dosing instruments $[4,28]$. Liquid medication delivery devices alone are insufficient in reducing medication errors as provider communication problems contribute to confusion about medication administration, particularly for complex instructions $[10,25]$. 
Total patients attended pediatric outpatient during the study period (twice a week for three months) $n=1856$
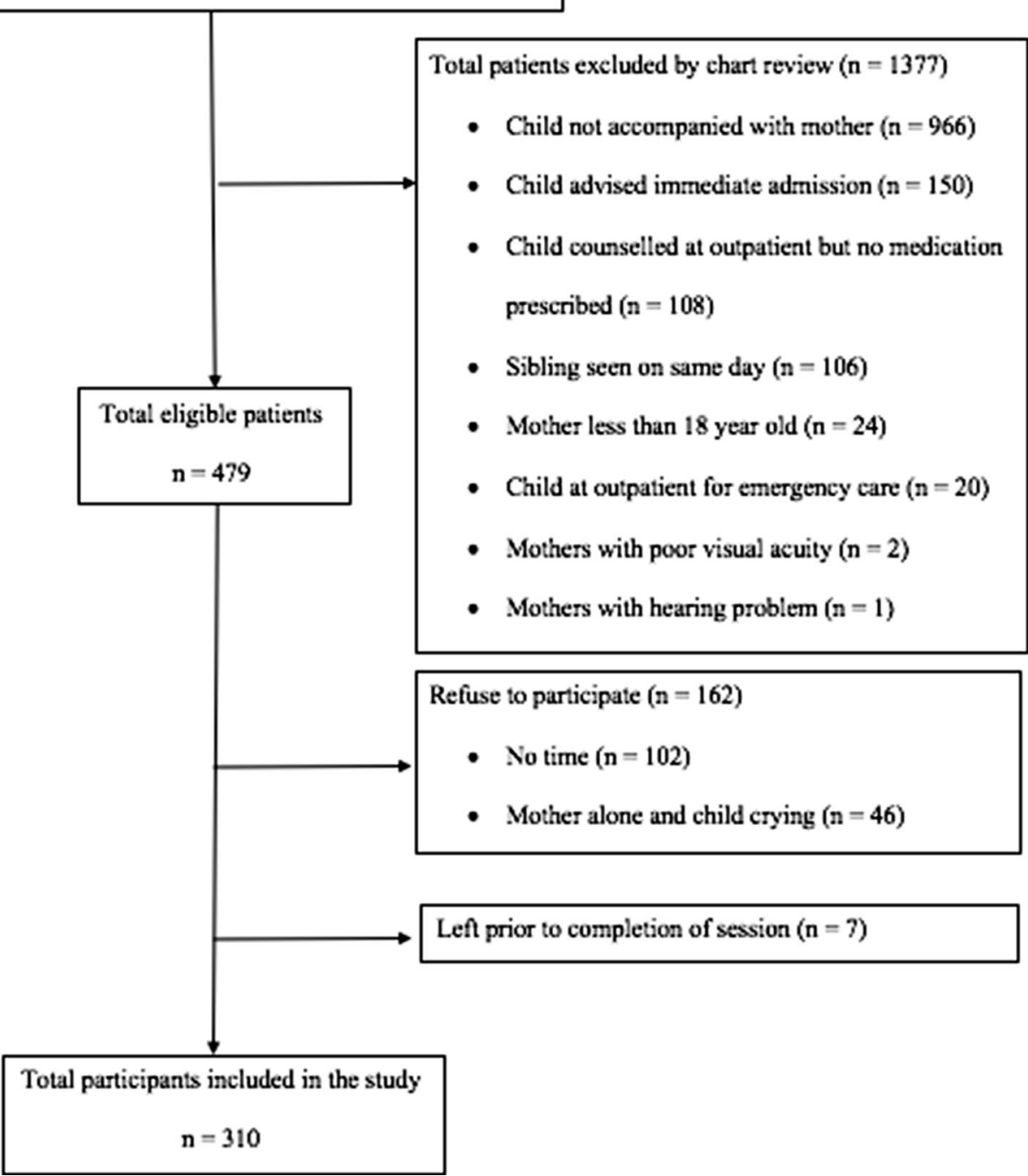

Fig. 1 Flow chart of the recruitment process of the participants in the study

\section{Limitations}

The study is a cross-sectional analysis and therefore, we cannot draw conclusions on causality. The design also does not allow conclusion over mothers ability to learn, which would have required a follow-up design. There could be a potential learning effect of the oral instruction, on the pictogram intervention, however we believe that this effect was minimal as the order of measurement with various volumes and devices was random and the results of measuring errors were not discussed with the mothers. The effect of the pictogram intervention was measured immediately, and the study was not designed to measure long-term effects. By when the mothers would forget the pictogram and whether they would remember to use it in an emergency remain unclear. We did not include a control group as each mother acted as her own control. The study was performed as an experimental set-up in the outpatient settings of hospital and thus, might not reflect the home environment of the mothers. The dosing errors were assessed using hypothetical doses, which might not be the way the mothers dose at home. The mothers recruited in our study were predominantly from rural areas with low education, thus the results are not generalizable to other populations. 


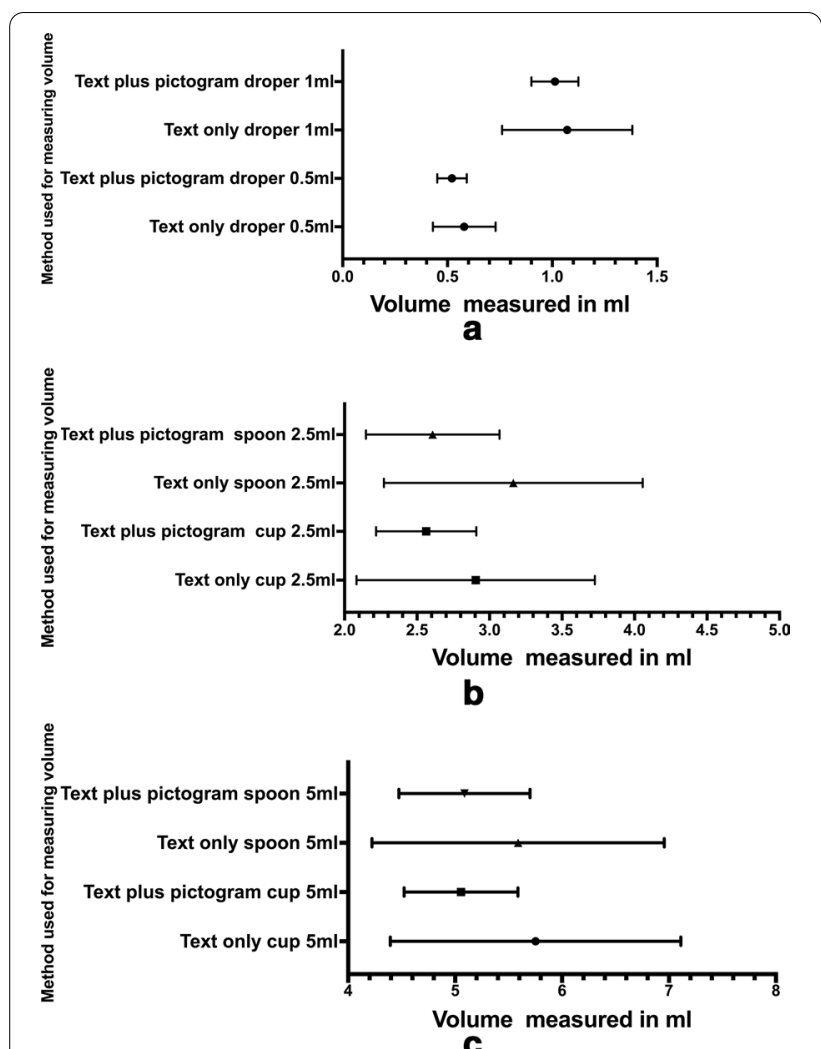

Fig. 2 Whisker Box plots for actual volumes measured by the mother for different volumes and measuring devices

\section{Recommendations}

Pictograms can help in parent information and empowerment needed to reduce medication errors, as they can be an effective mode of communicating correct doses to uneducated parents. However, reducing medication errors cannot be the sole responsibility of parents. The health professional including the prescribers and the pharmacists should be made aware of the medication errors by the parents and that simple tools like pictogram can significantly reduce them. Parents should be instructed to use calibrated devices and take care not to lose them. Pharmaceutical companies should provide extra calibrated devices with the liquid medications and additionally such devices should be available with pharmacies.

\section{Conclusions}

Pictogram-based medication consultation can reduce the risk of LMDE by mothers. A pictogram can be an effective provider-parent communication tool for parents with a low education status. Health care workers should be sensitized regarding the problem of dosing errors and should be motivated to use strategies such as pictograms to decrease these errors.

\section{Abbreviations}

LMDE: Liquid medication dosing errors; NCCMERP: American National Coordinating Council for Medication Error Reporting And Prevention; LMIC: Low-and-middle income countries; OPD: Outpatient department; TOMS: Text only measurement session; TPMS: Text plus pictogram measurement session; OR: Odds ratio; aOR: Adjusted odds ratio.

\section{Supplementary Information}

The online version contains supplementary material available at https://doi. org/10.1186/s40359-021-00584-9.

Additional file 1: Additional Table 1. Different measuring devices and the corresponding doses used in text only and text plus pictogram measuring session.

Additional file 2: Additional Figure 1. Measuring devices and their pictograms used in the study. Fig 1 a Picture of actual measuring devices used in the study; Fig $1 \mathrm{~b}$ and $1 \mathrm{c}$ Pictograms of dropper for measuring 0.5 $\mathrm{ml}$ and $1 \mathrm{ml}$, respectively; Fig $1 \mathrm{~d}$ and 1 e Pictograms of measuring cups for $2.5 \mathrm{ml}$ and $5 \mathrm{ml}$, respectively; Fig $1 \mathrm{f}$ and $1 \mathrm{~g}$ Pictograms of calibrated spoons for measuring $2.5 \mathrm{ml}$ and $5 \mathrm{ml}$, respectively.

Table 5 Multivariate analyses of dependent variable for dosing error for calibrated spoon measuring $2.5 \mathrm{~mL}$ in $\mathrm{mothers}(\mathrm{n}=310)$

\begin{tabular}{|c|c|c|c|c|}
\hline \multirow[t]{2}{*}{ Variable } & \multirow[t]{2}{*}{ Adjusted OR } & \multicolumn{2}{|l|}{$95 \% \mathrm{Cl}$} & \multirow[t]{2}{*}{$P$ value } \\
\hline & & Lower & Upper & \\
\hline Age in months ${ }^{\mathrm{a}}$ & 1.08 & 1.01 & 1.17 & 0.026 \\
\hline \multicolumn{5}{|l|}{ Family type } \\
\hline Nuclear & Referent & Referent & Referent & Referent \\
\hline Joint & 2.83 & 1.44 & 5.56 & 0.002 \\
\hline \multicolumn{5}{|l|}{ Mothers education } \\
\hline Uneducated-primary school & Referent & Referent & Referent & Referent \\
\hline Middle school-higher secondary & 0.34 & 0.16 & 0.73 & 0.006 \\
\hline Graduate-post graduate & 0.03 & 0.01 & 0.08 & $<0.001$ \\
\hline
\end{tabular}

${ }^{\text {a }}$ Adjusted for age 


\section{Acknowledgements}

We are thankful to all the study participants for taking part in the study. We would also like to thank the Dean, Dr. MK Rathore, and Medical Director, Dr. VK Mahadik, RD Gardi Medical College, Ujjain, India for the support that was provided us in undertaking the study.

\section{Authors' contributions}

PP and AP participated in the conception and design of the study. PP and AM collected the data. PP, AM and AP performed the statistical analysis. PP and AP drafted the first version of the manuscript. PP, AM, and AP revised the paper critically for substantial intellectual content. All authors read and approved the final manuscript.

\section{Funding}

Open access funding provided by Karolinska Institute. Pawan Patidar received financial assistance from the Indian Council of Medical Research as MD dissertation thesis grant (Grant No. 3/2 June -2017/PG-Thesis-HRD (2)) under guidance of Ashish Pathak. The funding body had no role in the design of the study and collection, analysis, and interpretation of data and in writing the manuscript.

\section{Availability of data and materials}

The datasets used and/or analyzed during the current study is available from the corresponding author on reasonable request.

\section{Declarations}

\section{Ethics approval and consent to participate}

The institutional ethical committee of RD Gardi Medical College, Ujjain, Madhya Pradesh, India approved the study (Approval number IEC/RDGMC/171). An informed written consent was obtained from mother participated in the study in the local language, Hindi.

\section{Consent for publication}

Not applicable.

\section{Competing interests}

The authors declare that they have no competing interests.

\section{Author details}

${ }^{1}$ Department of Paediatrics, Ruxmaniben Deepchand Gardi Medical College, Ujjain, Madhya Pradesh 456010, India. ${ }^{2}$ Department of Women and Children's Health, International Maternal and Child Health Unit, Uppsala University, Uppsala, Sweden. ${ }^{3}$ Department of Global Public Health, Health Systems and Policy: Medicines Focusing Antibiotics, Karolinska Institutet, Stockholm, Sweden.

Received: 3 September 2020 Accepted: 10 May 2021

Published online: 25 June 2021

\section{References}

1. NCCNRP - The National Coordinating Council for Medication Error Reporting and Prevention-Definition of medication error. United States of America 2020. https://www.nccmerp.org/about-medication-errors. Accessed 19 July 2020.

2. Hoppu K, Sri Ranganathan S, Dodoo AN. Realities of paediatric pharmacotherapy in the developing world. Arch Dis Child. 2011;96(8):764-8.

3. Yin HS, Mendelsohn AL, Wolf MS, Parker RM, Fierman A, van Schaick L, Bazan IS, Kline MD, Dreyer BP. Parents' medication administration errors: role of dosing instruments and health literacy. Arch Pediatr Adolesc Med. 2010;164(2):181-6.

4. Yin HS, Dreyer BP, van Schaick L, Foltin GL, Dinglas C, Mendelsohn AL. Randomized controlled trial of a pictogram-based intervention to reduce liquid medication dosing errors and improve adherence among caregivers of young children. Arch Pediatr Adolesc Med. 2008;162(9):814-22.

5. Walsh KE, Mazor KM, Stille CJ, Torres I, Wagner JL, Moretti J, Chysna K, Stine CD, Usmani GN, Gurwitz JH. Medication errors in the homes of children with chronic conditions. Arch Dis Child. 2011;96(6):581-6.
6. Ravikiran SR, Shivarajashankara YM. Dosing ability of Indian parents for liquid medication. Indian Pediatr. 2011;48(2):153-4.

7. MacLeod S, Peterson R, Wang Y, Li Z, Gui Y, Schaller J. Challenges in international pediatric pharmacology: a milestone meeting in Shanghai. Paediatr Drugs. 2007;9(4):215-8.

8. Harris LM, Dreyer BP, Mendelsohn AL, Bailey SC, Sanders LM, Wolf MS, Parker RM, Patel DA, Kim KYA, Jimenez JJ, et al. Liquid medication dosing errors by Hispanic parents: role of health literacy and English proficiency. Acad Pediatr. 2017:17(4):403-10.

9. Falagas ME, Vouloumanou EK, Plessa E, Peppas G, Rafailidis PI. Inaccuracies in dosing drugs with teaspoons and tablespoons. Int J Clin Pract. 2010;64(9):1185-9.

10. Bailey SC, Pandit AU, Yin S, Federman A, Davis TC, Parker RM, Wolf MS. Predictors of misunderstanding pediatric liquid medication instructions. Fam Med. 2009;41(10):715-21.

11. Wittich CM, Burkle CM, Lanier WL. Medication errors: an overview for clinicians. Mayo Clin Proc. 2014;89(8):1116-25.

12. Miller MR, Robinson KA, Lubomski LH, Rinke ML, Pronovost PJ. Medication errors in paediatric care: a systematic review of epidemiology and an evaluation of evidence supporting reduction strategy recommendations. Qual Saf Health Care. 2007;16(2):116-26.

13. Joshi P, Bavdekar SB. Liquid drug dosage measurement errors with different dosing devices. Indian J Pediatr. 2019;86(4):382-5.

14. Hameen-Anttila K, Kemppainen K, Enlund H, Bush Patricia J, Marja A. Do pictograms improve children's understanding of medicine leaflet information? Patient Educ Couns. 2004;55(3):371-8.

15. Yin HS, Mendelsohn AL, Fierman A, van Schaick L, Bazan IS, Dreyer BP. Use of a pictographic diagram to decrease parent dosing errors with infant acetaminophen: a health literacy perspective. Acad Pediatr. 2011;11(1):50-7.

16. Kheir N, Awaisu A, Radoui A, El Badawi A, Jean L, Dowse R. Development and evaluation of pictograms on medication labels for patients with limited literacy skills in a culturally diverse multiethnic population. Res Social Adm Pharm. 2014;10(5):720-30.

17. Yin HS, Parker RM, Sanders LM, Mendelsohn A, Dreyer BP, Bailey SC, Patel DA, Jimenez JJ, Kim KA, Jacobson K, et al. Pictograms, units and dosing tools, and parent medication errors: a randomized study. Pediatrics. 2017;140(1):e20163237.

18. UNDP: Madhya Pradesh-Economic and Human Development Indicators. India; 2007-2008. https://www.undp.org/content/dam/india/docs/ madhyapradesh_factsheet.pdf.

19. NHFS-4: National Family Health Survey-4-Ministry of Health and Family Welfare, Government of India, International Institute for Population Sciences, Mumbai. India; 2015-16. http://rchiips.org/nfhs/pdf/NFHS4/MP_ FactSheet.pdf. Accessed 19 July 2020.

20. Yin HS, Parker RM, Sanders LM, Dreyer BP, Mendelsohn AL, Bailey S, Patel DA, Jimenez JJ, Kim KA, Jacobson K, et al. Liquid medication errors and dosing tools: a randomized controlled experiment. Pediatrics. 2016;138(4):e20160357.

21. OpenEpi: Open Source Epidemiologic Statistics for Public Health, Version. from www.OpenEpi.com. Accessed 19 July 2020.

22. Almazrou S, Alsahly H, Alwattar H, Alturki L, Alamri M. Ability of Saudi mothers to appropriately and accurately use dosing devices to administer oral liquid medications to their children. Drug Healthc Patient Saf. 2015:7:1-6.

23. Solanki R, Mondal N, Mahalakshmy T, Bhat V. Medication errors by caregivers at home in neonates discharged from the neonatal intensive care unit. Arch Dis Child. 2017;102(7):651-4.

24. Tzimenatos L, Bond GR. Pediatric Therapeutic Error Study G: Severe injury or death in young children from therapeutic errors: a summary of 238 cases from the American Association of Poison Control Centers. Clin Toxicol (Phila). 2009;47(4):348-54.

25. Yin HS, Dreyer BP, Moreira HA, van Schaick L, Rodriguez L, Boettger S, Mendelsohn AL. Liquid medication dosing errors in children: role of provider counseling strategies. Acad Pediatr. 2014;14(3):262-70.

26. Yin HS, Parker RM, Sanders LM, Dreyer BP, Mendelsohn A, Bailey S, Patel DA, Jimenez JJ, Kim KA, Jacobson K, et al. Effect of medication label units of measure on parent choice of dosing tool: a randomized experiment. Acad Pediatr. 2016;16(8):734-41. 
27. Sobhani P, Christopherson J, Ambrose PJ, Corelli RL. Accuracy of oral liquid measuring devices: comparison of dosing cup and oral dosing syringe. Ann Pharmacother. 2008;42(1):46-52.

28. Yin HS, Dreyer BP, Ugboaja DC, Sanchez DC, Paul IM, Moreira HA, Rodriguez L, Mendelsohn AL. Unit of measurement used and parent medication dosing errors. Pediatrics. 2014;134(2):e354-361.

29. Ryu GS, Lee YJ. Analysis of liquid medication dose errors made by patients and caregivers using alternative measuring devices. J Manag Care Pharm. 2012;18(6):439-45.

30. Samuels-Kalow ME, Stack AM, Porter SC. Parental language and dosing errors after discharge from the pediatric emergency department. Pediatr Emerg Care. 2013;29(9):982-7.

31. Yin HS, Vuong C, Parker RM, Sanders LM, Mendelsohn AL, Dreyer BP, Velazquez JJ, Wolf MS. Identifying and advancing best practices for the labeling and dosing of pediatric liquid medications: progress and challenges. Acad Pediatr. 2019;19(1):1-3.

32. Schillinger D, Machtinger EL, Wang F, Chen LL, Win K, Palacios J, Rodriguez M, Bindman A: Language, Literacy, and Communication Regarding
Medication in an Anticoagulation Clinic: Are Pictures Better Than Words? In: Advances in Patient Safety: From Research to Implementation (Volume 2: Concepts and Methodology). edn. Edited by Henriksen K, Battles JB, Marks ES, Lewin DI. Rockville (MD); 2005.

33. Yin HS, Wolf MS, Dreyer BP, Sanders LM, Parker RM. Evaluation of consistency in dosing directions and measuring devices for pediatric nonprescription liquid medications. JAMA. 2010;304(23):2595-602

34. Chan HK, Hassali MA, Lim CJ, Saleem F, Tan WL. Using pictograms to assist caregivers in liquid medication administration: a systematic review. J Clin Pharm Ther. 2015;40(3):266-72.

\section{Publisher's Note}

Springer Nature remains neutral with regard to jurisdictional claims in published maps and institutional affiliations.
Ready to submit your research? Choose BMC and benefit from:

- fast, convenient online submission

- thorough peer review by experienced researchers in your field

- rapid publication on acceptance

- support for research data, including large and complex data types

- gold Open Access which fosters wider collaboration and increased citations

- maximum visibility for your research: over 100M website views per year

At BMC, research is always in progress.

Learn more biomedcentral.com/submissions 